\title{
Development of a Computer Aided Transport Monitoring System (CATRAMS) for Manufacturing Organizations
}

\author{
Dipo Theophilus Akomolafe \\ Ph.D., MBCS, MNCS \\ Dept of Mathematical Sciences \\ Ondo State University of Science and Technology, \\ Okitipupa, Nigeria
}

\begin{abstract}
Presently, there are different types of monitoring systems and devices being used to monitor vehicles, products, processes and activities in manufacturing organizations. Each of these devices has their unique strengths and weaknesses but one problem that is common to them is that there is no knitted relationship between the devices and parameters necessary for effective and efficient monitoring system. Therefore, there is the need to develop a system that will address this shortcoming.

CATRAMS is an integration of computer and communication facilities to monitor and control movement of vehicles and goods. Its objectives are to provide detail information on movement of vehicles and reduce likely operational delays associated with movement of vehicles and goods. The development of the system was carried out by studying some existing devices to know their limitations, designing of road transport database, specifying hardware requirements and integrating the hardware and software resources to make a complete system. The system was tested using data collected from some manufacturing industries and it was found out that detail information about movement of vehicles and goods could be provided by the system.
\end{abstract}

Keywords- transport; manufacturing; database; hardware; communication, route; goods; passengers.

\section{INTRODUCTION}

The benefits of transport monitoring systems and other systems based simply on mini and micro -computers particularly robotics are now widely recognized and used in all spheres of endeavour. In the area of transportation, computer is used to aid the initial techno-economic feasibility study, the actual design and construction of transportation means and other related activities. However, computer is yet to be fully integrated into monitoring of transportation operations in the manufacturing organization. This inadequacy is having negative impact on the productivity and capacity utilization of machinery and efficient and effective use of human resources. Manufacturing organization is an entity that is set up primarily to transform raw materials into finished goods. It is evident from the activities of this type of organization that its operations revolve around mobility.

Raw materials, processing equipment and employees are needed to be moved from one place to another so also finished goods must be appropriately delivered. It is therefore clear that transportation is crucial to the realization of their corporate goals and objectives.

It is visible that an organization cannot enjoy one hundred percent commitment from its employees generally especially those that are charged with the responsibility of transporting raw materials and finished goods from one place to another. Consequently, various measures are being put in place to address this problem by organizations but a deep study of some of these measures showed that they cannot totally curtail some of the practices of vehicle drivers. It is against this backdrop that this study is being carried out. The study is primarily intended to meet the challenges posed by moving both human and materials resources from one place to another.

Transportation system generally can be classified broadly into three types; land, air and water. The concern of this study is land transportation with emphasis on road transportation. Road transportation is the movement of goods and passengers from one place to another by a means which can be bicycle, motorcycle or vehicle. Road transportation has a multi-modal feature and because of this, it has the ability to penetrate every area and is the most commonly used mode of transportation in every part of the world and by extension the most widely used means of transportation in manufacturing organizations to move men and materials from one place to another. Road transportation can either be regulated or unregulated. It is regulated when the mode (bicycle, motor cycle and vehicle) of transportation is owned, managed and controlled by a manufacturing organization having more than five vehicles in their fleet while unregulated system refers to when organization rely on outside operator. This study is focused on regulated system because of its relative advantages over other modes, the possibility of defining definite route(s) of vehicle, ease of identification, flexibility in statistical analysis, ease of information, openness of operation, international coloration and possibility of modeling and simulation base on available statistics.

\section{OBJECTIVES}

Many problems are associated with road transportation and these ranges from uninformed road accident, diversion of products//commodities, faults, misappropriation of proceeds 
among others. These problems had wreaked havoc and will continue to have negative impact on the growth of manufacturing organization unless an effective system is put in place to prevent its occurrence where possible and reduce its effects. The primary objective of this study is to develop an effective and efficient system for monitoring of vehicles used in manufacturing organizations. Other objectives are to:

$\begin{array}{cccc}\text { a) extend computer application to the area of } \\ \text { monitoring } & \text { of } & \text { vehicles } & \text { in }\end{array}$
manufacturing organization;

b) demonstrate the possibility of using a computer program to control fleet of vehicles in a manufacturing organization;

c) use real time computing in transport monitoring and

d) provide effective and reliable means to remove delays and sharp practices of employees associated with transport operation.

\section{METHODOLOGY}

The development of CATRAMS involves three definite and distinct phases and these are the design of the software, hardware specification and the interconnection of hardware and software. Before going into the details of the design, it is imperative to examine some existing systems, computer network, communication facilities, monitoring and control devices in order to determine the platform for the development of CATRAMS and identify the computer and communication resources required for the system.

\section{DESCRIPTION OF DEVELOPMENTS IN COMPUTER AND COMMUNICATION}

Computer Network is the interconnection of computer resources with communication system in order to achieve the full exchange of information within the network and allow sharing of resources. In recent time, computer network has gained wide acceptability in its application in business and science as a tool in the design and implementation of systems. However, the ability and capability of computer network, as a pre requisite for effective monitoring has over the years not been fully extended to monitoring of vehicles in the manufacturing sector. There had been some technological developments in computer and communication over the last few years that can be used to design and implement effective monitoring systems for road transportation. Among the recent developments are:

a) The introduction of digital transparent network, which meant that many of the functions that were hitherto carried out inside network could now be, carried out either inside or outside the network;

b) The range of services that could be offered by the administration had increased and this had come about because the switches that are now being employed in the network are controlled not by hardwired logic but by computers and this allows the exchange to perform many more functions in addition to switching simple cells.

c) The availability of wireless communication system.
Therefore the development of CATRAMS is made possible due to these advancements that simply involve among other things the integration of advances in computer networks into the operation of regulated transport system.

\section{Existing Systems of Vehicle Monitoring}

Monitoring in its real sense means the act of guiding a situation in order to prevent (or avoid) likely events from occurring in the course of the situation or to know that any of the likely event(s) has occurred and suggest probably way(s) to report any occurrence. Monitoring had been accepted as a scientific tool that is widely used to guide likely occurrence and to categorically state the required action to take in case the unexpected happens. Researchers and corporations had developed many systems that are used either on stand-alone or along with other device(s) for the purpose of monitoring. A careful observation of these systems generally showed that the process of monitoring basically involve communication between source and remote locations [10]. [7] identified the various procedures involved in the act of communication from source to remote locations and proposed that the effectiveness of any system developed for such purpose depends to a great extent on the communication components.

The various components of a network as identified by [4] include inter connection of computer, transmitter, transmission medium the receiver and other appropriate hardware depending on the type of network. These components are in conformity with identification proposed in [3]. The numerous existing monitoring devices were designed using different technologies and adopted diverse modes in their implementation. While some were implemented manually, some were activated electrically, robotically and mechanically. Among the existing devices are Automatic Point Location (APL) and Specific Time Alert (STA) [8] and enhancing road transportation through geospatial technology [1].

These and other monitoring devices that were not actually designed for vehicle monitoring in the manufacturing organization possess some negative effects which posed challenges for further researches into monitoring devices. Some of these effects are similar to those identified in [6] and these facilitated the design of Hazard Alert Device (HAD) by Bell Inc. The primary objective of HAD was to remove the negative effects of previous devices and provide effective monitoring device. The shortcomings of APL and STA are:

a) lack of communication between the base station and remote location

b) lack of adequate information on vehicles plying the road

c) inadequate information on goods in transit along the network

However shortly after HAD was introduced, it was discovered that the limitations of the devices it was supposed to overcome were not totally removed and in addition to this, the followings shortcomings were discovered:

(i) Limitation of coverage area

(ii) They were not a stand-alone system 
(iii)

They were developed with technologies that were gradually becoming obsolete

The system restrained its scope of applicability

It supported only voice communication

\section{COMPONEnTS OF THE EXISTING SyStem}

Some of the existing systems basically involved the use of communication equipment that supports voice information within a specific area and within a pre-determined range. The major rationale for the design of most of the existing systems was to be able to communicate with vehicles within a certain range.

The concern for such design device was not to monitor vehicles throughout the course of the journey but to determine the probable arrival at a specified location. Automatic Point Location, which is a widely used system, is more of a security device than a monitoring system. Though it has the ability to indicate the particular location of vehicle at every point in time but cannot provide detailed information of the vehicle in case of accident. This feature is common to most of the existing devices; they have security capability but lacked functional database.

Walkie-talkie and radiophone are other devices for monitoring [9]. The application of these systems is simple and flexible. It involved communication-using walkie-talkie between radiophone room and drivers. However there is a limit to the coverage area of both radiophone and walkie-talkie among other deficiencies. These devices are wholly communication facilities and their actions and results can only be fed into the computer manually for storage and future references.

It is clear from the above analysis that monitoring systems generally are made up of either communication infrastructures or combination of this with computer facilities. Some of the existing devices were made using communication systems like transmitter, transmission medium and receiver integrated with computer or communication facilities alone. Therefore, the conception of CATRAMS is being directed towards addressing these limitations and to provide a stress and hitch free monitoring device that is wider in scope, applicability and coverage.

\section{DESSIGN}

The design of CATRAMS involved three major phases; the design of software, hardware and integration of both. Succinctly, the system is basically inter-connection of computer resources with communication facilities. The computer resources required are computer hardware and software.

Computer Hardware: The computer hardware used in the design of the system were system unit with inbuilt wireless facilities and peripheral devices like input, output, printers and scanner, network cables and MODEM.

Software: The first phase was the design of the software. In designing the software, the first consideration was to examine the type(s) of information that could be exchanged on a network and these are data, sound and video. These forms had been examined in [1] and [2]. The software required for the system is the system software and application packages. The operating systems used are Windows Server 2003 for the servers and Windows XP for other client computers. The program application was developed using Visual Basic 6 (VB 6) language. Visual Basic 6 was chosen for the development and implementation of the application program because it provides fast and easy properties to create application for Microsoft Windows.

In addition it offers users with a complete set of tools to simplify rapid application development. Visual Basic is made up of two parts; Visual and Basic. The visual aspect generally refers to the method used to create the Graphical User Interface (GUI). Rather than writing numerous lines of code to describe the appearance and location of interface elements, it makes it possible to simply drag and drop rebuilt objects into a specific place on screen.

The Basic part refers to the Beginners All-purpose Symbolic Instruction Code) language, a language that is generally used by more programmers than any other language in the history of computing. Visual Basic has evolved from the original BASIC language and now contains several hundred, statements, functions and keywords, many of which relate directly to the windows GUI.

\section{PRogram Description}

CATRAMS is a system designed to provide up to date information on vehicles transporting goods and passengers from one location to another using any of the current systems especially those that works via satellite and radio communication as connectivity. It also established a computer aided monitoring system in which computers can be connected from different remote stations (clients) to the central computer system (server). This system runs on the network to provide the server with adequate and timely information that will trigger an action to be performed anytime there is a request and aid decision making.

CATRAMS is a window-based system designed to run on Windows 95/98, NT or ME developed using Visual Basic 6.0. The system runs with executable file (TMS.EXE) after which a welcome screen appeared and displays the system information and the author. After the welcome screen, the log in screen would be displayed. The login is a control measure to authenticate user id and password. When the user id is certified correct, the main menu will be displayed showing the following information:

\section{A. GENERAL INFORMATION}
1) System Header
2) System Administration
3) Parameter setup

\section{B. TECHNICAL INFORMATION}

1) Vehicle Information

2) Drivers Information

3) Vehicle Movement Information

4) Goods/Passenger Information

\section{INPUT PROCESSING}

1) Data Input 


\section{REPORT UTILITIES}

1) Backup Data Files

2) Restore Data Files

3) Reset Data Files

\section{Program Design}

The program design utilized the visual design process, which is peculiar to VB generally, and the integrated development environment, which allowed the application program to be developed, run, tested and debugged.

\section{VISUAL DESIGN PROCESS: DESIGNING CATRAMS GUI WITH VISUAL BASIC FOLLOWED THESE STEPS:}

\section{A. Definition of requirements}

B. Planning of the user interface which centered on the production of process plan/model of the interface, planning the user interface element and planning/implementing standards and mechanism

C. Building the user interface element which involved creating and modifying user interface element and functionality /

\section{User feedback and monitoring. This involved prototype} testing and monitoring and / application of user feedback

The actual design of the program began with the gathering of data. These data were the components of information imperative for effective monitoring. At this stage, all the information gathered was analyzed; sorted and universal description was allotted to each of the situation to be monitored. The information included those relating to the organization, the driver(s), vehicle(s) goods/passengers and the journey. The following technical sub-headings were identified and used:

1) Drivers

2) Vehicles

3) Journey

4) Goods/Passengers

5) Users log in

All the above listed technical sub-headings and relevant data underneath each of them were modeled into a relation before their table structure were appropriately designed.

\section{TABLE Definition}

The following tables formed from the identified headings were defined:

Drivers

This table contained relevant data on all the drivers engaged by the user organization. It showed the name, residential address, department in which the driver is attached in case of situation where driver may be borrowed for a particular assignment, date of birth, license number, date of issue and employment number among other relevant data included. The table is shown in Table 1

Vehicles

All data pertaining to each of the vehicles were described in the vehicle data table structure. The table contains information relating to the historical background and current information of all the vehicles and the status of their ownership. It clearly showed data, which clearly distinguished vehicles owned by the organization from those on hire. This is shown in Table 2

\section{Journey}

A brief summary of the journey being undertaken by all the vehicles at every point in time was defined in the table structure of journey. The table journey was specifically designed for the purpose of distinguishing the destination of each of the vehicles and purpose of the journey. In additionally, the journey data is the backbone of the monitoring system as it contained pertinent data relating to the journey and likely occurrences along the journey. In a nutshell, the table contains data that are being monitored by the system from the point of departure till destination. The table structure is as shown in Table 3.

Goods/Passengers

It is pertinent for an organization to maintain accurate record of goods and passengers. This is to enable the organization to have a compendium of information on goods and passengers for use, when:

a) Unexpected occurrence like accident occurs.

b) Take accurate stock of goods and luggage.

c) Keep tracks of the goods and passengers' entrance and departure

The table structure is shown in Table 4

The interfaces were designed using Visual Basic 6.0

The user interface consists of a set of screens. In other words, a screen is called whenever the user clicks on one of the application's forms. A screen can be composed of several components that constitute different parts of the screen content i.e. different record of the database. From the scenarios and function specifications discussed above, the following interrelated set of screens was developed:

Entry Login Screen: This screen is launched and accessed from the Internet, using a browser. It is a HTML page meant for controlling access to designated areas.

Vehicle Registration Screen: Here a user can view the list of all registered vehicles within the organization and other details of the vehicles.

Journey Screen: From this screen a user has access to all the fields that relate to any vehicle journey.

Drivers Screen: From the vehicle screen a user can enter the drivers screen on _Enter Driver from where he/she can search for any driver.

Beside these, other screens are goods, passengers and route

\section{IMPLEMENTATION}

The required Software was installed on networked computers (servers and workstations) appropriately. The computers and other devices were connected together using appropriate cables. The table was populated by using the appropriate forms designed for that purpose. The following forms had been designed to allow easy entry of data; vehicle, 
driver, journey, passenger and goods. The user is merely expected to click any of the interface forms to display the appropriate form. At this level, the system makes use of Microsoft Access 2007 as the back engine. Information can be exchanged among facilities available within the level since the computer hardware used in each of the nodes had been interconnected to allow free communication.

\section{Data Entry Forms}

Data entry forms are the interfaces designed to allow users to enter, modify and delete data values of a record in the database. The data entry forms serve as a link between the user and the database files. It contains features such as text boxes, command buttons, pictures, charts, labels and other features. These features facilitate data update operations. The data entry forms designed in this research and which are for each of the tables are for the purposes of insertion of new records, modification of existing record, deletion of record, saving record, cancelling of operation and close operation .

\section{Password Authorization System}

Gaining access to the main program requires that each user must enter his or her name and password. Where invalid password is entered, access to the program is denied. The procedure of password verification involves matching the entered password with the stored password. If the name and password are valid, access to the program will automatically be granted but is denied if there is a mistake in any of them. The procedure of password creation is simple and interactive hence new users can always be added. Thereafter, any desired transaction can be carried out using the appropriate form

Hardware:

The hardware required and used for its implementation:
Digital camera: This is used to take the images of any scene that may occur during the journey

Multimedia Handset: This is another device that can be used to take images of any scene, recording and communicating with the base station

Computers: The computers used for the implementation of the system have a minimum 512MB Random Access Memory (RAM) and 45 G Hard Disk.

The system was tested using two different manufacturing companies and it was found out that:

a) Movement of vehicles was effectively monitored from the point of departure till they got to their final destination Information relating to goods in transit could be accessed at all the workstations

b) Accurate data relating to the passengers were made available immediately it was desired

c) Diversion of products by drivers was quickly detected

\section{CONCLUSION}

The design of CATRAMS was compelled by the shortcomings of the present devices of monitoring. These devices served as the platform for the design of the system. A database of a manufacturing organization was proposed using relational database model. The application program was developed using Visual basic and was installed in computers in a network after the installation of the appropriate operating systems. The system was tested using real data from two manufacturing companies in different locations and the results showed significant improvement over the existing systems.

TABLE 1 DRIVERS' TABLE

\begin{tabular}{|l|l|l|l|l|l|}
\hline No & NAME & TYPE & SEE & KEY & \\
\hline 1 & Drvnum & Text & 15 & Primary & Driver's employment number \\
\hline 2 & Drvsname & Text & 20 & & Driver's surname \\
\hline 3 & Drvfname & Text & 20 & & Driver' first name \\
\hline 4 & Drvadd & Memo & 0 & & Driver's residential address \\
\hline 5 & Drvlcno & Text & 25 & & Driver's license number \\
\hline 6 & Drvlctype & Text & 15 & & Driver's license type \\
\hline 7 & Drvdept & Text & 15 & & Driver's department \\
\hline
\end{tabular}


TABLE 2 TABLE DEFINITIONS FOR VEHICLE.

\begin{tabular}{|c|c|c|c|c|c|}
\hline $\mathrm{NO}$ & NAME & TYPE & SIZE & KEY & DESCRIPTION \\
\hline 01 & Vehno & Text & 15 & Primary & Vehicle Number \\
\hline 02 & Typeofveh & Text & 50 & & Type of Vehicle \\
\hline 03 & Chasisno & Text & 25 & & Chasis Number \\
\hline 04 & Engine & Text & 25 & & Engine Number \\
\hline 05 & Yrofmk & Date/Time & 8 & & Year of Make \\
\hline 06 & Vehcolor & Text & 12 & & Vehicle Colour \\
\hline 07 & Inspol & Text & 25 & & Insurance Policy \\
\hline 08 & Spdometer & Long & 4 & & Speedometer range \\
\hline 09 & Maxspall & Long & 4 & & $\begin{array}{l}\text { Maximum speed } \\
\text { allowed }\end{array}$ \\
\hline 10 & Ownername & Text & 30 & & Owner's Name \\
\hline 11 & Date Hired & Date & & & Date Hired \\
\hline 12 & H Duration & Long & 2 & & Duration of Hire \\
\hline 13 & HAmt & Long & 10 & & Amount paid for hiring \\
\hline
\end{tabular}

TABLE 3 TABLE DEFINITION OF JOURNEY

\begin{tabular}{|l|l|l|l|l|}
\hline NO & NAME & TYPE & SZE & DESCRIPTION \\
\hline 01 & Jnycode & Text & 6 & Journey code \\
\hline 02 & Jnyppse & Memo & 0 & Journey purpose \\
\hline 03 & Jnydepart & Text & 25 & point of departure \\
\hline 04 & Jnydte & Date/Time & 8 & date of the journey \\
\hline 05 & Jnydest & Date/Time & 8 & Destination \\
\hline 06 & Jnytime & Long & 4 & estimated distance of the journey \\
\hline 07 & Jnydist & & 8 & probable time of arrival \\
\hline 08 & Ptmofarrvl & Date/Time & 8 & actual time of arrival \\
\hline 09 & Tmofarrvl & Date/Time & 8 & difference between probable time \\
& Date/Time arrival \\
and actual time of arrival
\end{tabular}


TABLE 4 TABLE DEFINITIONS FOR PASSENGERS

\begin{tabular}{|c|c|c|c|c|c|}
\hline $\mathrm{NO}$ & NAME & TYPE & SIZE & KEY & DESCRIPTION \\
\hline 01 & Vnum & Text & 15 & Primary & Vehicle number \\
\hline 02 & Gd/Passallowm & Text & 20 & & $\begin{array}{l}\text { Goods and Male passengers } \\
\text { Allowed }\end{array}$ \\
\hline 03 & Gds/Passallf & Text & 20 & & $\begin{array}{l}\text { Goods and female passengers } \\
\text { Allowed }\end{array}$ \\
\hline 04 & Gd/Passdepartf & Text & 20 & & $\begin{array}{l}\text { Goods and female passengers } \\
\text { at departure }\end{array}$ \\
\hline 05 & Gd/Padepartm & Text & 20 & & male passengers at departure \\
\hline 06 & GdPassall & Text & 20 & & $\begin{array}{l}\text { Total goods and passengers } \\
\text { Allowed }\end{array}$ \\
\hline 07 & Drsnfordiff & Memo & 0 & & reason for difference \\
\hline 08 & Others & Memo & 0 & & Others \\
\hline
\end{tabular}

\section{REFERENCES}

[1] Akinyokun O.C. (1994) Computers and Programming Using Fortran. Second edition. Ondo state New Era Commercial Press, Alagbaka G.R.A., Akure, Ondo State.

[2] Akomolafe, D.T. et all, (2009) "Enhancing road monitoring and safety through the use of geospatial technology," International Journal of Physical Sciences Vol.4 (5) pp 343-348

[3] Aram Falsafi, Kaveh Pahlavam, Ganing Young (1995) "Transmission Techniques for Radio LANS- A Comparative Performance Evaluation Using Ray Tracing" (www,cwins.wpi.edu)

[4] Falaki S.O. (2000). "Hardware Requirements for the Implementation of a Computer Network,". Course Material.
[5] Lacky, R. W., Salz,J.,and Weldon, E.J., Jr., (2003) "Principles of Data Communications", j McGraw-Hill Book Company, New York, Martin, James, (1998) "Telecommunications and the Computer," Prentice-Hall, Inc., Englewood Cliffs, N. J.,

[6] Miller, M.J., Vucetic B and Barry, L (1993) - Satellite Communications Mobile and Fixed Services\| Norwell, M A Kluiver Academic Publishers

[7] Miya, K. (ed.) (1975) "Satellite communications Engineering," Kyowa Book Company, Tokyo,

[8] Ola, J.S., (2007) -Development of Specific Alert System for Road Transportation\| International of Physical Sciences 207 Vol. 3(4)

[9] Taub, Herbert, and D. L. Schilling, (1971) Principles of Communication Systems, McGraw-Hill Book Company, New York.

[10] Wilkinson, R.I., (1956) "Theories for Toll Traffic Engineering in the USA," Bell System Tech. 